\title{
ANÁLISIS SOBRE EL ALMACENAMIENTO TÉRMICO EN LA EDIFICACIÓN
}

\author{
(ANALYSIS OF THE THERMAL STORAGE IN CONSTRUCTION)
}

J. Luis Esteban Sáiz, Dr. Ing. Industrial

ICCET/CSIC/ESPAÑA

$190-10$

Fecha de recepción: 24-X-91

\section{RESUMEN}

En primer lugar se hace una exposición sobre el tratamiento con carácter general que está teniendo la aplicación de la energía solar pasiva en la edificación, dentro del ámbito de la CEE, bien en programas de investigación o en previsiones de ahorro energético y disminución de la contaminación del medio ambiente para pasar, posteriormente, a los sistemas de acumulación térmica por calor latente y calor sensible, analizándose en este último caso los producidos por cantos rodados y a base de agua.

A continuación se desarrollan los trabajos que se llevaron a cabo en el Instituto sobre módulos experimentales, donde se analizó la influencia de la distribución de masa en el interior del módulo, asi como el ahorro energético experimentado sobre dos casetas análogas con invernadero adosado a la fachada Sur, pero uno de ellos sin sistema de acumulación térmica, a base de cantos rodados, definiéndose un indice térmico global, que considera, conjuntamente, los factores de ahorro energético y confort térmico.

\section{SUMMARY}

The paper begins with and explanation of the general treatment which the application of passive solar energy receives in construction, within the $E E C$, either in research programmes or in the estimates for energy saving and reducing of the environmental pollution. The author then goes on to analyse the systems of thermal accumulation through latent heat and sensible heat. The types of heat produced by means of water together with pebbles are analysed in the latter case.

Further on, there is a description of the work carried out at the Institute on experimental modules. The object of analysis was the influence of the mass distribution inside the module, and also the energy saving tested on two analogous houses with the conservatory leaning against the South facade, one of which did not have the thermal storage system based on pebbles. These experiments helped to define the global thermal index, which takes into consideration both the energy saving factors and the thermal comfort.

\section{INTRODUCCIÓN}

El hablar en la actualidad de energía solar parece un poco fuera de tono, puesto que al estar el petróleo en el mercado a unos precios asequibles, constituye el principal combustible generador de energía. No obstante estas consideraciones pueden invertirse totalmente si, por cualquier fenómeno, se incrementara el precio del petróleo frente a un tipo de energía, la solar, que la única alteración que puede sufrir es la climática pero $\sin$ afectar a su costo, en este caso podriamos ver, como ha ocurrido en otras ocasiones, que la opinión general incluida la científica se vuelca hacia otros tipos de energia.
La Directiva del Consejo de la C.E.E., del 21 del XII de 1988, sobre los Productos de Construcción, contempla que los productos deben ser apropiados para aquellas obras que sean idóneas para su uso, teniendo en cuenta la economía y en este sentido deben de cum. plir unos requisitos esenciales en los que están contemplados seis acciones previsibles: 1) resistencia y estabilidad; 2) seguridad en caso de incendio; 3) higiene, salud y medio ambiente; 4) utilización; 5) protección contra el ruido, y 6) ahorro de energía y aislamiento térmico. Este último aspecto, independiente de valoraciones de la instalación como rendimientos, aislamientos térmicos, etc., que así consta en el Documento interpretativo correspondiente, tiene gran relación con el diseño de la vivienda considerada. 
En el programa de demostración MONITOR, sobre realizaciones efectuadas utilizando como base la energía solar pasiva después de analizar las correspondientes monitorizaciones de evaluación del comportamiento energético, bajo las consideraciones básicas de:

- ahorro energético,

- confort térmico,

sin que se origine un sobrecoste importante de la edificación, debido a la incorporación de elementos constructivos adicionales en relación con la construcción convencional, se ha podido comprobar en numerosos ejemplos que se han alcanzado ahorros energéticos del orden del $35 \%$ en relación con el sistema tradicional.

Recientemente se ha publicado, por parte de la dirección General XII "Ciencia, Investigación y Desarrollo" de la C.E.E., un estudio (20) sobre la utilización de la energía solar en la edificación, dentro de la Comunidad Europea, y las perspectivas de utilización para el año 2000 y el año 2010, así como consecuencia de esta previsible utilización, la disminución de contaminación atmosférica en los diferentes periodos. Por lo que se refiere a nuestro pais, y en plan de resumen, destacaremos que España, en el año 1990, ha contribuido con el $12,5 \%$ del ahorro energético total producido en la Comunidad, debido a la utilización de la energía solar pasiva; las previsiones, para el año 2010 , son que la energía solar pasiva tendrá un incremento del $73 \%$ con relación al año 1990 y el enfriamiento pasivo, de gran importancia en nuestro país, contribuiría con cerca del $50 \%$ y la iluminación natural con el $11,5 \%$ de la energía total que se emplee para cada uno de estos fines determinados.

La incorporación en la edificación de la energía solar por sus aplicaciones, así como las distintas técnicas que se han llevado a cabo para su aprovechamiento, la han conferido una categoria propia dentro del campo de los que pudiéramos llamar nuevas energías, o mejor dicho energias alternativas, aunque parece paradójico que se hable en estos términos cuando nos referimos a la estrella SOL con un período de funcionamiento de 4,500 millones de años. Pero lo que puede considerarse nuevo es su aplicación a sabiendas de los fenómenos físicos que se producen y que se tra$\tan$ de provocar, unas u otras, en beneficio de las disposiciones constructivas que se hayan realizado, así como en el caso inverso generar unas soluciones constructivas que $\sin$ ir en detrimento del aspecto arquitectónico se incremente la energía térmica en determinado sentido, bien sea por elevación del nivel térmico interior o, por el contrario, por eliminación del excedente térmico interno.

En cualquier caso, nos encontramos en la regulación o modificación de las condiciones externas para que

(c) Consejo Superior de Investigaciones Científicas

Licencia Creative Commons 3.0 España (by-nc) a través de ellas se consiga en el interior del edificio unas condiciones ambientales lo más próximas a un grado, en el que el cuerpo humano se encuentre en situación óptima técnicamente.

\section{GENERALIDADES}

Independientemente de las funciones de transferencia que se desarrollan en el envolvente del hábitat, desde el ambiente exterior al interior del local o vivienda, es necesario que esas variaciones de clima se mantengan o bien se puedan regular por el propio envolvente, con el fin de corregir el ambiente interno deseado, por lo cual el proceso se complica aun más, ya que, si bien es cierto que dentro de determinados climas las oscilaciones diarias permanecen dentro de unos márgenes pequeños, en otros ambientes sufren grandes variaciones, y no digamos ya cuando la referencia la tomamos en distintas estaciones del año, donde se originan factores que alteran los procesos de transferencia, puesto que en algunos casos la transferencia energética no tiene el sentido de interior al exterior, como ocurre normalmente en temporada de invierno, sino que es al contrario, de exterior al interior, es decir, introduciendo carga térmica del exterior del local o vivienda, lo que implica tener que refrigerar para eliminarla y alcanzar el punto de equilibrio térmico.

Quizás en los países del norte de Europa, prácticamente la transferencia térmica no tenga apenas cambio de sentido, pero en los países meridionales como España, en gran parte de las regiones se experimenta dicha variación. Recordemos, por ejemplo, dos ciudades con condiciones climáticas dispares, como Córdoba y Burgos, donde los datos que obtenemos de temperatura de diseño para el nivel $99 \%$ extraido de la distribución de frecuencias (2) y (3) es el indicado en la tabla I.

TABLA I

\begin{tabular}{|c|c|c|}
\hline CIUDAD & VERANO & INVIERNO \\
\hline CÓRDOBA & 38,8 & $-1,2$ \\
\hline BURGOS & 30,8 & $-7,2$ \\
\hline
\end{tabular}

Es decir, hay que pasar de un calentamiento en el interior del edificio a un enfriamiento en épocas de verano, por lo tanto a la hora de diseñar un sistema habrá que hablar de sistemas combinados donde estén contemplados ambos mecanismos de transferencia energética.

Los procesos de calentamiento primordialmente están basados en las acciones de los sistemas acristalados que, debido a sus caracteristicas intrinsecas, efectúan 
una función de amplificación de la energía térmica como consecuencia de la doble faceta de transmisión de la energía térmica solar (radiación infrarroja de corta longitud de onda) a través del acristalamiento, y prácticamente impermeables a la emisión calorifica de larga longitud de onda (superior a $5 \mu \mathrm{m}$ ) que se origina en las paredes u objetos interiores como consecuencia de la elevación de su temperatura. Este fenómeno denominado "efecto invernadero" también puede producirse con otros materiales con diferente rendimiento, en función de sus características energéticas.

No hay que olvidar los porcentajes de energía que se reciben en dias claros en función del espectro de radiación electromagnética, según puede apreciarse en la tabla II.

\section{TABLA ॥}

\begin{tabular}{|c|c|}
\hline $\begin{array}{c}\text { ENERGIA SOLAR } \\
\%\end{array}$ & $\begin{array}{c}\lambda \\
(\mu \mathrm{m})\end{array}$ \\
\hline 95 & $0,3 \cdot 2,4$ \\
1,2 & $<0,3$ \\
3,6 & $>2,4$ \\
\hline
\end{tabular}

Dentro del $95 \%$ que comprende el espectro de radiación de 0,3 a 2,4 $\mu \mathrm{m}$ se encuentra prácticamente la totalidad de la energía térmica recibida.

La energía solar, que penetra a través de los acristalamientos, es absorbida prácticamente en su totalidad por las paredes del edificio, ya que solamente el $2 \%$ aproximadamente sale por los vidrios hacia el exterior después de múltiples reflexiones en las paredes.

La entrada de flujo térmico a la vivienda, por radiación solar, no tiene un proceso continuo a lo largo del dia, puesto que es función de las condiciones ambientales, nubosidad, contaminación atmosférica, etc., así como es determinante la ubicación de la vivienda, altitud, latitud y otros aspectos como pueden ser vientos, sombras, etc.

Esta entrada de flujo, además de ser variable en función del tiempo (noche), llega un momento que se extingue totalmente, entonces es determinante poder aprovechar al máximo las condiciones de acumulación que se han realizado durante los periodos diurnos, donde ha habido aporte energético.

En muchos casos, durante esos períodos diurnos se pueden producir temperaturas superiores a la de confort, es decir, sobrecalentamientos (foto 1), lo que provocaría por parte del usuario una actuación sobre la ventilación por ejemplo abriendo la ventana y provocando corrientes de aire para eliminar ese exceso tér(c) Consejo Superior de Investigaciones Científicas Licencia Creative Commons 3.0 España (by-nc)

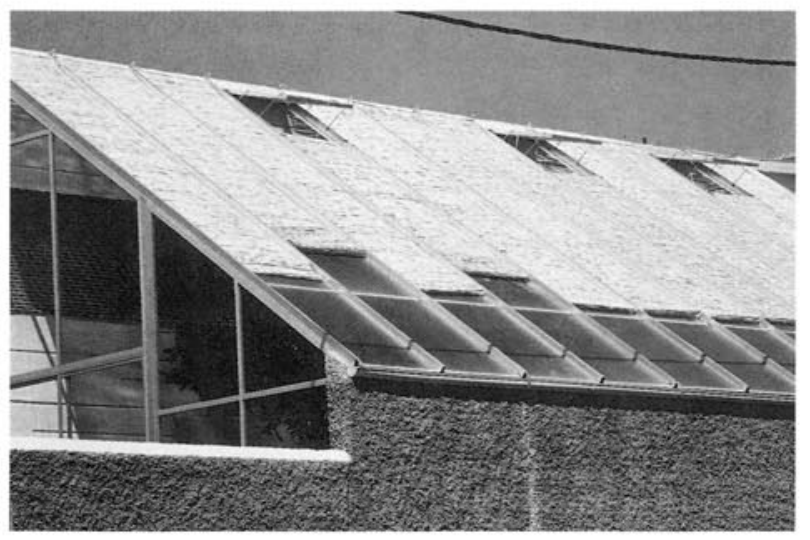

Foto 1.-Actuación del usuario sobre el invernadero para evitar el sobrecalentamiento.

mico, o también en función del clima exterior pueden actuar sistemas automáticos, con el consabido problema que estos mecanismos más o menos complicados pueden representar en lo referente a averías, desajustes, etc.

Con la idea de ahorro energético, este excedente de energía habría que almacenarlo para posteriormente desprenderlo de forma controlada en función de las necesidades energéticas internas, que se darian en la noche, cuando los aportes energéticos exteriores son nulos y las pérdidas térmicas máximas.

En el supuesto de la existencia de un sistema de acumulación térmica, su comportamiento o mecanismo de actuación en época de invierno sería como un sistema dinámico o "activo", que en los períodos diurnos se carga de energía térmica para luego descargarse en los períodos nocturnos.

Si en vez de considerar estos fenómenos como una macro - transformación térmica, analizamos con mayor precisión el proceso de flujo de calor desde la superficie externa hacia el interior del local, puede apreciarse que se trata de un estado térmicamente dinámico con continuos cambios de sentido de flujos; así, si subdividimos el cerramiento en una serie de láminas elementales, el flujo de calor produce en cada lámina una elevación de temperatura, y el calor empleado en esto se almacena en ella. Así, cada lámina recibe menos calor y aumenta menos su temperatura que la precedente. De esta forma, la última lámina del muro recibe menos calor y eleva menos su temperatura que la primera. Una vez que la superficie externa ha alcanzado su máximo de temperatura comienza a enfriarse, con lo que se produce el proceso inverso. El calor almacenado en el muro fluye hacia dentro y hacia fuera, con lo que tenemos un proceso de enfriamiento. De esta manera, cualquier plano del muro sigue ciclos inversos de enfriamiento y calentamiento. La amplitud de la temperatura interna es menor que la de la onda exhttp://informesdelaconstruccion.revistas.csic.es 


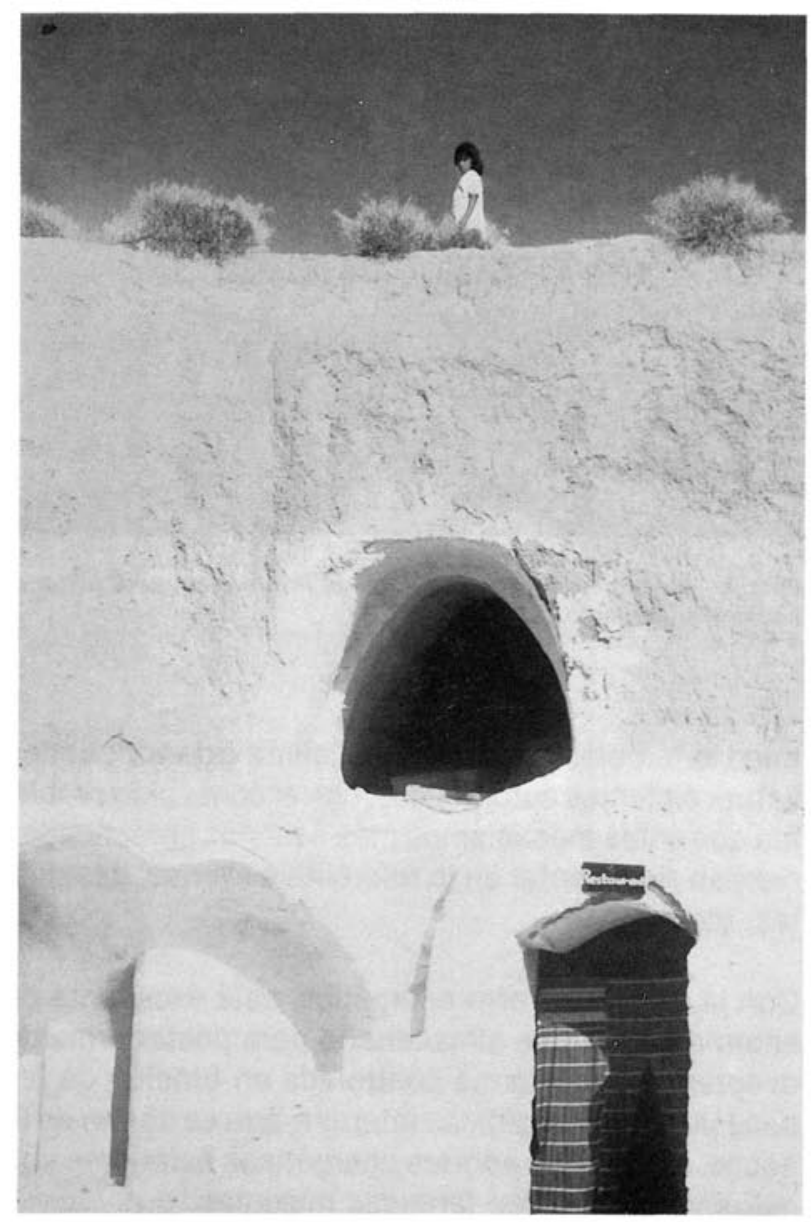

Foto 2. Aspecto de viviendas subterráneas.

terna, y los máximos y mínimos se ven desfasados en una proporción que dependerá de los espesores y las propiedades termofísicas de los cerramientos.

El aprovechamiento de las acumulaciones de carga y descarga, para regularizar los niveles térmicos internos, es importante en los casos en que las variaciones diurnas de temperaturas exteriores sean amplias $y$, especialmente, cuando la media de la temperatura exterior queda dentro de las amplitudes de temperaturas interiores aceptadas.

Con el fin de poder aprovechar el excedente térmico generado en las épocas referidas, se están efectuando trabajos con almacenamiento de tipo estacional, auxiliándose como sistema de captación solar a través de colectores solares de aire que, mediante ventiladores, envian el aire caliente al sistema de acumulación en lecho de piedras (cantos rodados) con periodos casi estacionarios descargándose al alcanzar una temperatura determinada (15). Este sistema, que está en fase experimental, podría conducir a un ahorro energético considerable, aún teniendo en cuenta los elevados gastos de inversión del sistema acumulador y su amortización.
Dentro de los sistemas acumuladores estacionales sin aporte exterior por medios activos, pueden considerarse las viviendas de tipo subterráneo (foto 2) que, como ya se comentó en la referencia (1), al encontrarse a profundidades variables de 3 a 8 metros, el ambiente interior goza de unas condiciones de habitabilidad bajo el punto de vista térmico bastante aceptable.

\section{SISTEMAS DE ACUMULACIÓN TÉRMICA}

Para la utilización de un material, como sistema de acumulador térmico, es necesario que el cuerpo que podemos considerar sólido, con motivo de la captación calorifica, aumente su energía interna, lo que se constata por elevación de su temperatura; es decir, que se produce una agitación molecular, incrementándose las oscilaciones respecto a las posiciones moleculares iniciales, traduciéndose en un aumento de su calor sensible. Si continuáramos este proceso de aporte calorifico crece la agitación molecular hasta llegar al punto de fusión, donde la agitación es muy grande en la mayoría de las moléculas, destruyendo el estado anterior y su disposición molecular, originándose un cambio de estado aumentando su entropia. La incorporación de la energía necesaria para producir ese cambio de fase sólido a líquido, a temperatura constante, se denomina calor latente.

Si incrementásemos el aporte térmico, llegariamos a procesos de una mayor agitación molecular alcanzándose el estado de vapor. En el primer caso considerado, si los procesos descritos se desarrollasen en sentido inverso, se produciria una cesión de calor. Partiendo del estado líquido, se produciría una cristalización con cesión del calor latente y posteriormente una disminución de su calor sensible, con disminución de su temperatura.

De lo mencionado anteriormente pueden desprenderse dos grandes campos de actuación donde se podrán desarrollar los procesos de almacenamiento térmico: uno por aprovechamiento de calor latente y otro por aprovechamiento del calor sensible.

En cualquier caso, los requerimientos de optimización que demandaremos de un sistema de acumulación serán los siguientes:

- Gran capacidad térmica de almacenamiento por unidad de masa o de volumen.

- Reversibilidad para un gran número de ciclos.

- Uniformidad de temperaturas.

- Posibilidad de almacenaje en recipientes.

- Empleo de productos no contaminantes y peligrosos.

- Larga durabilidad.

- Bajo coste tanto del material a emplear, como de la instalación necesaria y reducido mantenimiento de la misma.

http://informesdelaconstruccion.revistas.csic.es 
Por lo tanto, a la hora de seleccionar un sistema acumulador habrá que conjugar las diversas propiedades indicadas anteriormente con la aplicación y función, para el cual haya sido concebido, con otros factores más subjetivos, como pueden ser los de carácter arquitectónico, etc., en detrimento de su bondad para el almacenamiento térmico.

\subsection{Procedimientos del calor latente}

Para la posible utilización del calor producido por un cambio de fase al interior del edificio, es necesaria la cristalización de los dos componentes, que está condicionada por las miscibilidades de las fases líquidas y éstas, a su vez, según la naturaleza de las fases sólidas que cristalizan a la solución.

Para un estudio más detallado, habría que analizar los diagramas de fase de estos equilibrios, entre los que podemos destacar los siguientes:

- Completa miscibilidad de los componentes en las fases sólida y líquida.

- Sistemas itécticos con parcial miscibilidad en fase sólida.

- Sistemas peritécticos.

- Sistemas con formación de compuestos con punto de fusión congruente.

Los distintos materiales que se utilicen para esta aplicación, deberán reunir unas características primordiales para una adecuada funcionalidad, que podríamos resumir en los siguientes puntos:

- Alto calor de fusión por unidad de masa.

- Alta conductividad térmica para que el gradiente de temperatura entre la carga y descarga sea pequeño.

- Pequeños cambios de volumen durante el proceso de cambio de fase.

- Estabilidad química, dentro del rango de temperaturas de funcionamiento, que para esta aplicación podriamos definir como un rango de temperaturas de 18 a $50^{\circ} \mathrm{C}$.
- Reversibilidad para un gran número de ciclos.

- Posibilidad de almacenaje.

- Compatibilidad con el sistema de almacenaje (toxicidad, corrosión, inflamabilidad, etc.).

- Alta densidad, para poder almacenarse en pequeño volumen.

- Económico.

También existen ciertos compuestos químicos en los que el calor almacenado proviene del calor de cristalización al transformarse una fase sólida en otra sólida de distinta estructura cristalina, en los que la principal ventaja respecto a las anteriores son los pequeños cambios de volumen que experimentan.

Los compuestos que se emplean para este procedimiento de almacenamiento térmico, mediante cambio de fase, pueden dividirse en dos grandes familias: a) compuestos orgánicos, donde la parte más importante la constituyen las parafinas y una parte más reducida; b) los compuestos orgánicos y, por último, c) compuestos inorgánicos a base principalmente de sales hidratadas. Unos ejemplos de algunas de estas substancias de referencias $a, b$ ó $c$, pueden apreciarse en la tabla III, en la que se incluyen los compuestos orgánicos ( $a$ y b) y en la tabla IV, en la que se indican los compuestos inorgánicos.

Del análisis conjunto de las tablas III y IV, podemos ver la gran gama de sustancias o productos que efectúan cambio de fase, dentro de los entornos de temperatura previstos para las aplicaciones en la edificación.

Su utilización más extendida es como acumulación directa y se desarrolla entre temperaturas, donde el cambio de fase es próximo a la media diaria de la temperatura del aire.

No obstante, también existen otras aplicaciones dentro del campo de la edificación, donde su utilización se realiza a temperaturas superiores a las mencionadas, actuando como primaria de sistemas de intercam. biadores de calor.

TABLA III

\begin{tabular}{|l|c|c|c|}
\hline \multicolumn{1}{|c|}{ SUSTANCIA } & $\begin{array}{c}\text { PUNTO DE FUSIÓN } \\
\left({ }^{\circ} \mathbf{C}\right)\end{array}$ & $\begin{array}{c}\text { CALOR DE FUSIÓN } \\
\mathbf{( k J / k g )}\end{array}$ & $\begin{array}{c}\text { DENSIDAD } \\
\mathbf{( k g / \mathbf { m } ^ { 3 } )}\end{array}$ \\
\hline Parafina 20\% aceite & 22 & 195 & 780 \\
Parafina 5\% aceite & 42 & 195 & 780 \\
Hexadicano & 18 & 180 & 830 \\
Polietileno gricol & 21 & 148 & 1.180 \\
Octadecano & 26 & 240 & 840 \\
Ácido cáprico & 32 & 152 & 920 \\
Ácido láurico & 44 & 170 & 890 \\
\hline
\end{tabular}


TABLA IV

\begin{tabular}{|l|c|c|c|}
\hline \multicolumn{1}{|c|}{ SUSTANCIA } & $\begin{array}{c}\text { PUNTO DE FUSIÓN } \\
\left({ }^{\circ} \mathrm{C}\right)\end{array}$ & $\begin{array}{c}\text { CALOR DE FUSIÓN } \\
(\mathbf{k J} / \mathbf{k g})\end{array}$ & $\begin{array}{c}\text { DENSIDAD } \\
\left(\mathbf{k g} / \mathbf{m}^{\mathbf{3}}\right)\end{array}$ \\
\hline $\mathrm{KF} .4 \mathrm{H}_{2} \mathrm{O}$ & 19 & 230 & 1.440 \\
$\mathrm{Mn}\left(\mathrm{NO}_{3}\right)_{2} \cdot 6 \mathrm{H}_{2} \mathrm{O}$ & $21-25$ & 100 & 1.880 \\
$\mathrm{Li} \mathrm{NO} \mathrm{N}_{3} \cdot 3 \mathrm{H}_{2} \mathrm{O}$ & 30 & 330 & 1.370 \\
$\mathrm{Ca} \mathrm{Cl}_{2} \cdot 6 \mathrm{H}_{2} \mathrm{O}$ & 30 & 170 & 1.670 \\
$\mathrm{Na}_{2} \mathrm{SO}_{4} \cdot 10 \mathrm{H}_{2} \mathrm{O}$ & 32 & 251 & 1.460 \\
$\mathrm{Na}_{2} \mathrm{CO}_{3} \cdot 10 \mathrm{H}_{2} \mathrm{O}$ & 33 & 247 & 1.440 \\
$\mathrm{Ca} \mathrm{Br}_{6} \mathrm{H}_{2} \mathrm{O}$ & 37 & 128 & 2.070 \\
$\mathrm{Zn}\left(\mathrm{NO}_{3}\right)_{2} \cdot 6 \mathrm{H}_{2} \mathrm{O}$ & 36 & 150 & 2.070 \\
$\mathrm{Na}_{2} \mathrm{H} \mathrm{PO}_{4} \cdot 12 \mathrm{H}_{2} \mathrm{O}$ & 36 & 254 & 1.615 \\
$\mathrm{Na}_{2} \mathrm{~S}_{2} \mathrm{O}_{3} \cdot 5 \mathrm{H}_{2} \mathrm{O}$ & 48 & 215 & 1.630 \\
\hline
\end{tabular}

En esta línea, se puede citar la utilización en sistemas de calefacción por suelo radiante, donde las temperaturas medias de circulación del fluido suele variar dentro de unos márgenes de 28 a $48^{\circ} \mathrm{C}$. El producto, acumulador térmico, está distribuido en forma de recipientes estancos de pequeñas dimensiones, formando parte de la base donde se ancla el tubo de conducción, produciendo un ahorro energético, ya que en el momento que desciende la temperatura inferior a un nivel determinado entra en funcionamiento el acumulador con cambio de fase, despidiendo energía calorifica.

Dentro de las parafinas, su mayor ventaja estriba cuando se produce el enfriamiento y, por consecuencia, su cristalización siempre retorna a su forma original; $y$ la mayor desventaja es su bajo coeficiente de conductividad térmica $(0,15 \mathrm{~W} / \mathrm{mK})$, lo cual origina que se tarde bastante tiempo en la homogeneización.

También conviene destacar su expansión volumétrica durante el cambio de fase sólida a líquida, del orden del $5 \%$, asi como el peligro de inflamabilidad.

Por otro lado, las sales hidratadas poseen como principal ventaja su alto calor latente de fusión y densidades elevadas, que permiten un almacenaje compacto; pero por otra parte su desventaja más importante es que no siempre solidifican a la temperatura correcta y con la composición deseada.

Como consecuencia de este fenómeno, se han encontrado problemas con la repetitibidad de los ciclos de cambio de fase debido a la degradación progresiva que se origina en esas sustancias.

Esta degradación está motivada por la aparición de estratificaciones y sobreenfriamientos, es decir, al pro-

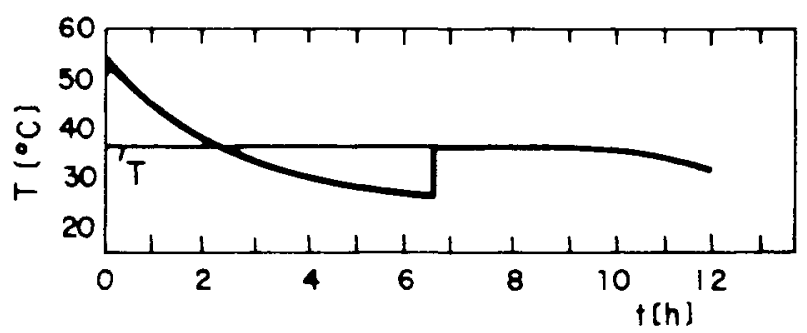

Fig. 1

ducirse un enfriamiento por debajo del punto de fusión del compuesto puede quedarse alguna parte en fase líquida, pudiendo dar lugar a que no se recupere el calor de fusión, o bien, que cambie el punto de fusión, estableciéndose en otro punto más bajo del previsto. El proceso de estratificación es como consecuencia de la separación progresiva de los distintos componentes después de producirse un número determinado de procesos de cambios de fases. En la figura 1 puede apreciarse un ejemplo de este fenómeno en el superenfriamiento que se origina en la sal hidratada.

$$
\mathrm{Na}_{2} \mathrm{HPO}_{4} \cdot 12 \mathrm{H}_{2} \mathrm{O} \text {. }
$$

En la actualidad, existen diversos procedimientos que eliminan prácticamente los anteriores inconvenientes, provocando la cristalización a la temperatura prevista cuando es como consecuencia del superenfriamiento y mediante la adicción de cargas (gel de sílice, etc.) en el caso de pérdida de capacidad de almacenamiento (9).

También dentro del procedimiento del calor latente, podriamos hablar del calor latente de vaporización, ya que al pasar un cuerpo al estado de vapor absorbe una 
cantidad de energía considerable denominada calor latente de vaporización que, para el caso del agua, tiene un valor de $600 \mathrm{Wh} / \mathrm{kg}$, pero en este caso el volumen ocupado por el vapor a la presión atmosférica es 1.700 veces superior, y como tiene un bajo calor especifico su capacidad de almacenamiento es muy bajo.

Conviene, pues, utilizar unos disolventes que tienen la propiedad de absorber grandes cantidades de vapores a una temperatura normal y restituir este vapor cuando la solución formada es calentada.

\subsection{Procedimientos de calor sensible}

Dentro del procedimiento del calor sensible pueden utilizarse materiales que formen parte de la propia estructura de la edificación, u otras que tengan como única finalidad el almacenamiento térmico. A continuación, en la tabla $V$ se exponen diferentes materiales con sus propiedades físico-térmicas más caracteristicas.
El almacenamiento térmico depende, principalmente, de la capacidad térmica del material, entendiéndose por tal el producto de la masa por su calor específico; por lo tanto, la energía almacenada por un cuerpo entre dos temperaturas inicial $\left(T_{0}\right)$ y final $\left(T_{1}\right)$ del proceso de calentamiento de un cuerpo tiene, por expresión:

donde:

$$
E=\int_{T_{0}}^{T_{1}} m \cdot C_{p} d T
$$

$\mathrm{m}=$ masa del cuerpo,

$C_{p}=$ calor específico a presión constante.

De los valores indicados en la tabla $V$ puede apreciarse cómo los materiales metálicos poseen una gran capacidad térmica, pero por otro lado no retienen durante cierto tiempo la energía calorífica acumulada, sino que se enfrian rápidamente, lo que conduciría en un sistema determinado a un mayor grado de aislamientos en el acumulador, independientemente del costo elevado del propio material.

TABLA V

\begin{tabular}{|l|c|c|}
\hline \multicolumn{1}{|c|}{ MATERIAL } & $\begin{array}{c}\text { DENSIDAD } \\
\left(\mathbf{k g} / \mathbf{m}^{3} \mathbf{)}\right.\end{array}$ & $\begin{array}{c}\text { CALOR ESPECíFICO } \\
\mathbf{( k J / k g ~ K )}\end{array}$ \\
\hline Adobe aligerado & 1.000 & 0,84 \\
Aire & 1,29 & 1,00 \\
Agua & 1.000 & 4,20 \\
Aluminio & 2.700 & 0,88 \\
Cantos rodados & $2.200-2.500$ & $0,70-0,92$ \\
Carbonato sódico & 2.510 & 1,09 \\
Cloruro cálcico & 2.510 & 0,67 \\
Cloruro potásico & 1.980 & 0,67 \\
Enfoscado de cemento & 1.570 & 1,00 \\
Fundición & 7.754 & 0,46 \\
Granito & 2.600 & 0,90 \\
Hormigón & 2.100 & 0,84 \\
Hormigón aligerado (bloques) & 600 & 1,00 \\
Ladrillo ligero & 1.300 & 0,84 \\
Ladrillo macizo & 1.900 & 0,84 \\
Madera & 600 & 1,20 \\
Mármol & 2.500 & 0,80 \\
Óxido de aluminio & 3.900 & 0,84 \\
Óxido de magnesio & 3.600 & 0,96 \\
Roca volcánica & 1.200 & 1,50 \\
Sulfato sódico & 2.700 & 0,92 \\
Tablero de fibras & 300 & 1,00 \\
Tejas & 1.900 & 0,78 \\
Tierra seca & 1.700 & 0,84 \\
Yeso & 1.300 & 1,00 \\
\hline
\end{tabular}


Lo que interesa, en un adecuado almacenamiento, es que la energía retenida sea liberada lentamente, lo cual depende del factor de proporcionalidad $(\gamma)$, denominado difusividad térmica, obtenido de la ecuación general de transmisión de calor, que tiene por expresión general:

$$
\frac{\partial \theta}{\partial t}=\gamma \nabla^{2} \theta+\frac{q_{v}}{c p \rho}
$$

$$
\frac{\partial \theta}{\partial t}=\underset{\text { tiempo }}{\text { gradiente de temperatura en función del }}
$$$$
\nabla^{2} \theta=\text { operador laplaciana, }
$$$$
\mathrm{q}_{\mathrm{v}} \quad=\text { capacidad de las fuentes internas de calor, }
$$$$
\mathrm{Cp}=\text { calor específico a presión constante, }
$$$$
\gamma=\text { difusividad térmica. }
$$

La difusividad térmica

$$
\gamma=\frac{\lambda}{\operatorname{cp} \rho}
$$

es una propiedad de la sustancia, que tiene gran importancia en los procesos de régimen transitorio y está relacionada con la velocidad de variación de la temperatura y nos da una medida de su inercia térmica. De la ecuación se deduce que en cada punto la variación de la temperatura con el tiempo es proporcional a $(\gamma)$, es decir, que la velocidad de variación de la temperatura

$$
\frac{\partial \theta}{\partial t}
$$

en cada punto del sólido, es tanto mayor cuanto mayor sea la difusividad térmica y, por lo tanto, a igual-
TABLA VI

\begin{tabular}{|l|c|}
\hline \multicolumn{1}{|c|}{ MATERIAL } & Difusividad térmica $\left(\mathrm{m}^{2} / \mathbf{s}\right)$ \\
\hline Hormigón & $6,1 \times 10^{-7}$ \\
Acero & $1,1 \times 10^{-5}$ \\
Madera & $1,3 \times 10^{-7}$ \\
Ladrillo & $5,5 \times 10^{-7}$ \\
Agua & $1,4 \times 10^{-7}$ \\
Aire $\left(20^{\circ} \mathrm{C}\right)$ & $1,9 \times 10^{-5}$ \\
\hline
\end{tabular}

dad de los restantes parámetros, tanto la estabilización de la temperatura en todos los puntos, como una alteración por un fenómeno térmico externo, será más rápida cuanto mayor sea la difusividad térmica. Como datos significativos de estos valores podemos apreciar la tabla VI, donde el acero y los metales, así como los cuerpos gaseosos en general, poseen una elevada difusividad con relación a otros materiales, y como consecuencia una baja inercia térmica.

Entre todos los materiales indicados en la tabla $\mathrm{V}$, el único líquido considerado es el agua, por poseer unas características óptimas debido al almacenamiento en relación con los otros materiales expuestos, ya que por unidad de volumen tiene una capacidad de almacenamiento dos veces superior a la del hormigón y tres con relación a la fábrica de ladrillo.

Otros liquidos que pueden ser usados en este sentido son los indicados en la tabla VII.

Estos liquidos orgánicos poseen características de atmacenamiento algo superiores a los materiales de construcción, ya que aunque la densidad tiene un valor medio, su calor específico es elevado. También pueden ser almacenados al tener un punto de ebullición elevado, pero sin embargo su principal inconveniente reside en su inflamabilidad.

TABLA VII

\begin{tabular}{|l|c|c|c|}
\hline \multicolumn{1}{|c|}{ SUSTANCIA } & $\begin{array}{c}\text { DENSIDAD* } \\
\left(\mathbf{k g} / \mathbf{m}^{3}\right)\end{array}$ & $\begin{array}{c}\text { CALOR ESPECÍFICO* } \\
\text { (kJ/kg K) }\end{array}$ & $\begin{array}{c}\text { PUNTO DE } \\
\left.\text { EBULLICIÓN }{ }^{\circ} \mathrm{C}\right)\end{array}$ \\
\hline Etanol & 2,4 & 790 & 78 \\
Propanol & 2,5 & 800 & 97 \\
Butanol & 2,4 & 809 & 118 \\
Isobutanol & 3,0 & 808 & 100 \\
Isopentanol & 2,2 & 831 & 148 \\
Octano & 2,4 & 704 & 126 \\
\hline
\end{tabular}

* Propiedades a temperatura $20-25^{\circ} \mathrm{C}$. 
Independientemente de aquellos materiales que tienen como función especial la estructural o arquitectónica, aunque lleven implícitos por sus características térmicas misiones de almacenamiento calorífico, tal es el caso por ejemplo del hormigón, los materiales más utilizados en las diversas realizaciones efectuadas son los cantos rodados y el agua, el primero cuya puesta en obra se efectúa generalmente en capas superpuestas y el segundo mediante recipientes (foto 3 ).

Analicemos a continuación, bajo diferentes aspectos funcionales, térmicos, de durabilidad, económicos, etc., el almacenamiento efectuado mediante cantos rodados o con el empleo del agua para aplicaciones de calentamiento ambiental y producción de agua caliente sanitaria dentro del margen de temperaturas de 20 a $80^{\circ} \mathrm{C}$, según se indica en la tabla VIII.

Foto 3.-Vista del sistema de acumulación a base de bidones de agua.

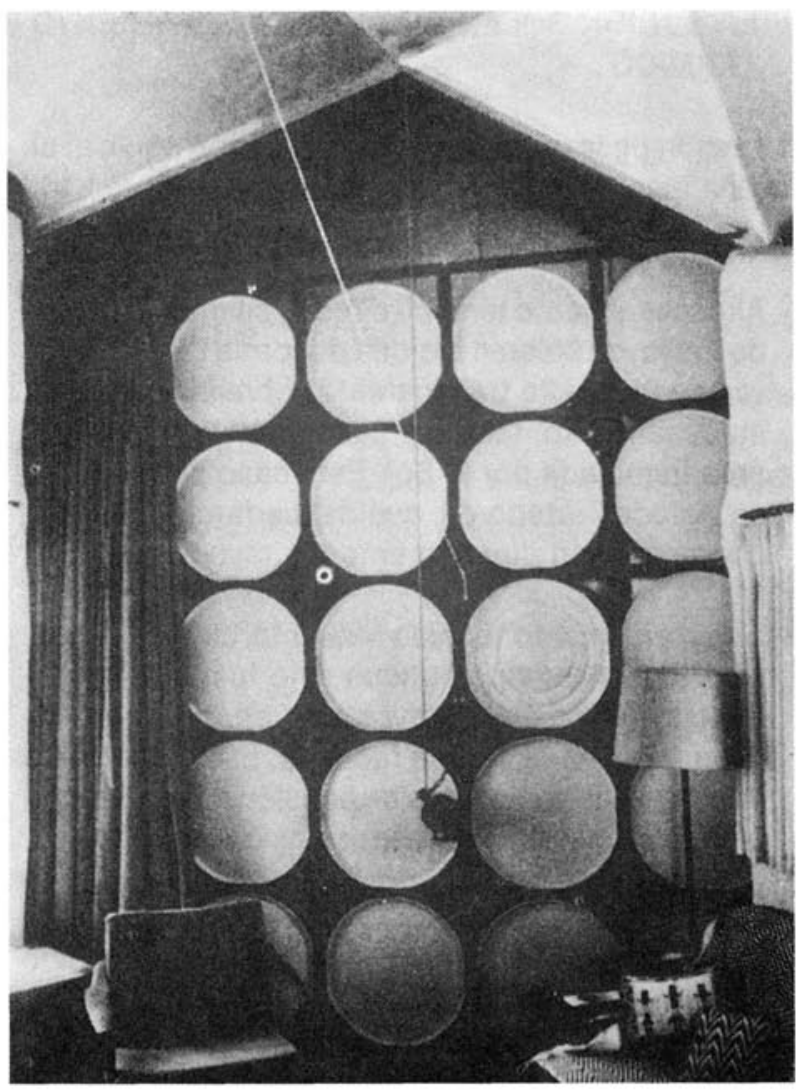

TABLA VIII

\begin{tabular}{|c|c|c|}
\hline CARACTERÍSTICA & AGUA & CANTOS RODADOS \\
\hline $\begin{array}{l}\text { A. COMPARACIÓN DE LOS MATERIALES } \\
\text { - Densidad } \\
\text { - Calor especifico } \\
\text { - Conductividad térmica } \\
\text { - Difusividad térmica } \\
\text { - Margen de temperaturas } \\
\text { - Capacidad de almacenamiento por unidad } \\
\text { de masa o volumen } \\
\text { - Estabilidad de ciclo térmico } \\
\text { - Aplicaciones, disponibilidad } \\
\text { - Coste }\end{array}$ & $\begin{array}{c}\text { Media } \\
\text { Alto } \\
\text { Baja } \\
\text { Media } \\
\text { Limitado } \\
\text { Baja } \\
\text { Buena } \\
\text { Todas } \\
\text { Barato }\end{array}$ & $\begin{array}{c}\text { Alta } \\
\text { Bajo } \\
\text { Baja } \\
\text { Muy amplio } \\
\text { Baja } \\
\text { Buena } \\
\text { Todas } \\
\text { Barato }\end{array}$ \\
\hline $\begin{array}{l}\text { B. COMPARACIÓN EN DIFERENTES SISTEMAS } \\
\text { DE ALMACENAMIENTO }\end{array}$ & & \\
\hline $\begin{array}{l}\text { - Gradiente de temperaturas durante } \\
\text { carga y descarga }\end{array}$ & Amplio & Amplio \\
\hline $\begin{array}{l}\text { - Efecto de estratificación } \\
\text { - Carga y descarga simultáneas }\end{array}$ & $\begin{array}{l}\text { Existe } \\
\text { Posible }\end{array}$ & $\begin{array}{l}\text { Existe } \\
\text { No posible }\end{array}$ \\
\hline $\begin{array}{l}\text { - Integración con sistemas térmicos } \\
\text { - Coste equipo de bombas, ventiladores, etc. }\end{array}$ & $\begin{array}{l}\text { Con sistemas de agua } \\
\text { Medio }\end{array}$ & $\begin{array}{l}\text { Con sistemas de aire } \\
\text { Medio }\end{array}$ \\
\hline - Fenómenos de corrosión & $\begin{array}{l}\text { Baja, empleando } \\
\text { inhibidores }\end{array}$ & No tiene \\
\hline $\begin{array}{l}\text { - Contaminación ambiental } \\
\text { - Durabilidad }\end{array}$ & $\begin{array}{l}\text { Ninguna } \\
\text { Larga }\end{array}$ & $\begin{array}{l}\text { Ninguna } \\
\text { Larga }\end{array}$ \\
\hline
\end{tabular}




\section{LA ACCIÓN SOLAR EN EL ALMACENAMIENTO TÉRMICO}

En función de la incidencia de la radiación solar, el almacenamiento térmico puede considerarse de tres formas diferentes:

- Almacenamiento térmico directo, cuando la acción de los rayos solares inciden de forma directa a través de un medio transparente sobre el área de almacenamiento; también puede definirse como el área iluminada por el Sol. Este caso puede darse en paredes interiores, suelos, cerramientos, etc., donde inciden directamente los rayos solares.

- Almacenamiento térmico indirecto, cuando el área de almacenamiento aunque esté fuera de la incidencia directa de los rayos solares, sobre ella recaen parte de la acción radiante. Este caso suele darse por las reflexiones de emisión calorífica o fenómenos convectivos intermedios ocasionados por la radiación directa.

- Almacenamiento térmico remoto, es el producido no por una radiación directa o indirecta, sino por un fenómeno de transferencia térmica directa; tal es el caso del almacenamiento con cantos rodados, donde la energía térmica es transferida del fluido portador como puede ser el aire, previamente calentando, a dichos cantos rodados.

Como se puede entender, el mayor rendimiento se produce en la forma primera, después en la segunda, y por último en el remoto, donde es preciso el calentamiento previo de una superficie para la generación de aire caliente.

Un esquema de estos tres modelos de almacenamiento pueden apreciarse en la figura 2.

En el primer caso, cuando haya un elemento transparente entre ambos la radiación recibida será:

$$
\mid \text { recibida }=\alpha . \tau . \mid
$$

donde:

1 = flujo energético sobre la superficie transparente, $\alpha=$ coeficiente de absorción,

$\tau=$ coeficiente de transmisión.

El valor $\alpha . \tau$ suele denominarse factor solar, como la relación entre la energía total que entra en un local y la energía que incide sobre la superficie transparente. En el caso de superficies acristaladas, el factor solar tiene un campo amplio de variación de 0,88 a 0,44 , en función de las caracteristicas superficiales de las caras reflectantes o la incorporación de óxidos metálicos en la propia masa.

(c) Consejo Superior de Investigaciones Científicas Licencia Creative Commons 3.0 España (by-nc)
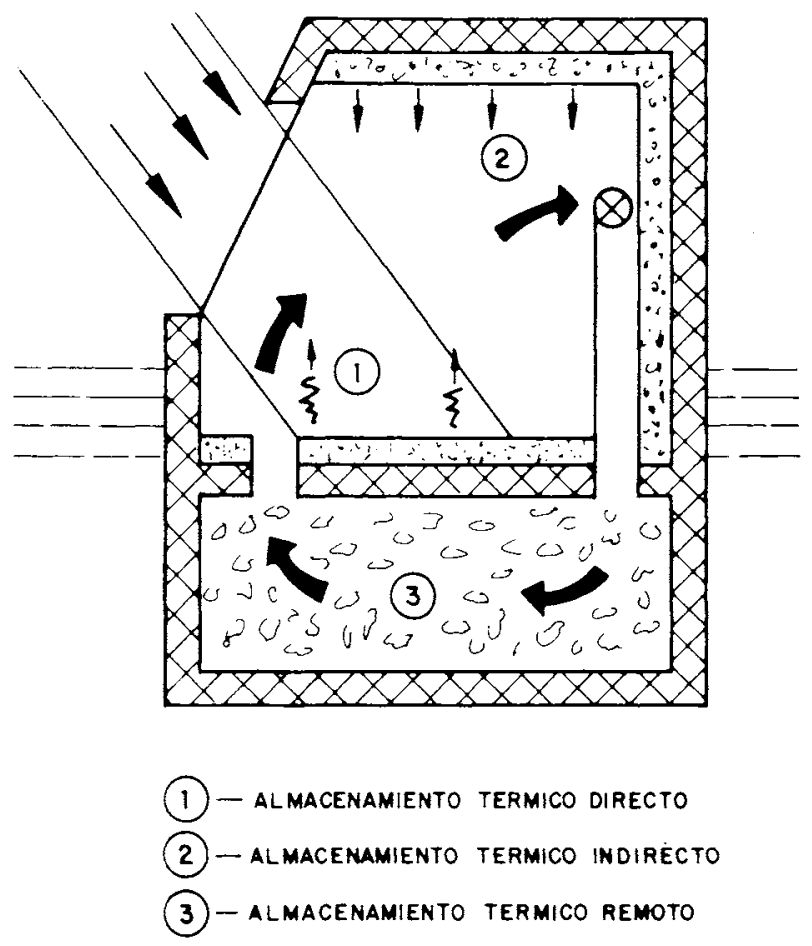

Fig. 2

En este aspecto, partimos de las dos tendencias que existen en el diseño arquitectónico con el fin de disminuir las pérdidas, unas basadas en la energía solar con grandes áreas acristaladas y cerramientos pesados en las orientaciones Sur, asi como construcciones pesadas por el interior con el fin de tener un gran poder de acumulación térmica, tanto de forma directa como indirecta y la otra, basada en el aislamiento, minimizando las pérdidas térmicas a base de altos niveles de aislamiento, pequeñas superficies acristaladas y edificaciones bastante herméticas.

La elección entre un criterio u otro, nunca es absoluto y siempre lleva aparejado ambos sistemas con distinto peso, aunque el primero es más adecuado para cuando se vaya a efectuar un régimen ocupacional continuado y, por el contrario, el segundo cuando resulta más beneficioso es para ocupación intermitente.

Se ha demostrado la influencia que tiene la masa térmica sobre las variaciones de temperatura que se experimentan en una habitación, siendo más amortiguada a medida que la masa térmica es más elevada.

En la figura 3, se han representado investigaciones que se han realizado por procedimientos de simulación, sobre una habitación con dos tipos de almacenamiento, uno directo y el otro indirecto, ambos de hormigón y de igual área de recepción donde al ir variando el espesor de la masa del almacenamiento indirecto se iba reduciendo las variaciones de temperatura en el interior del local (17). 


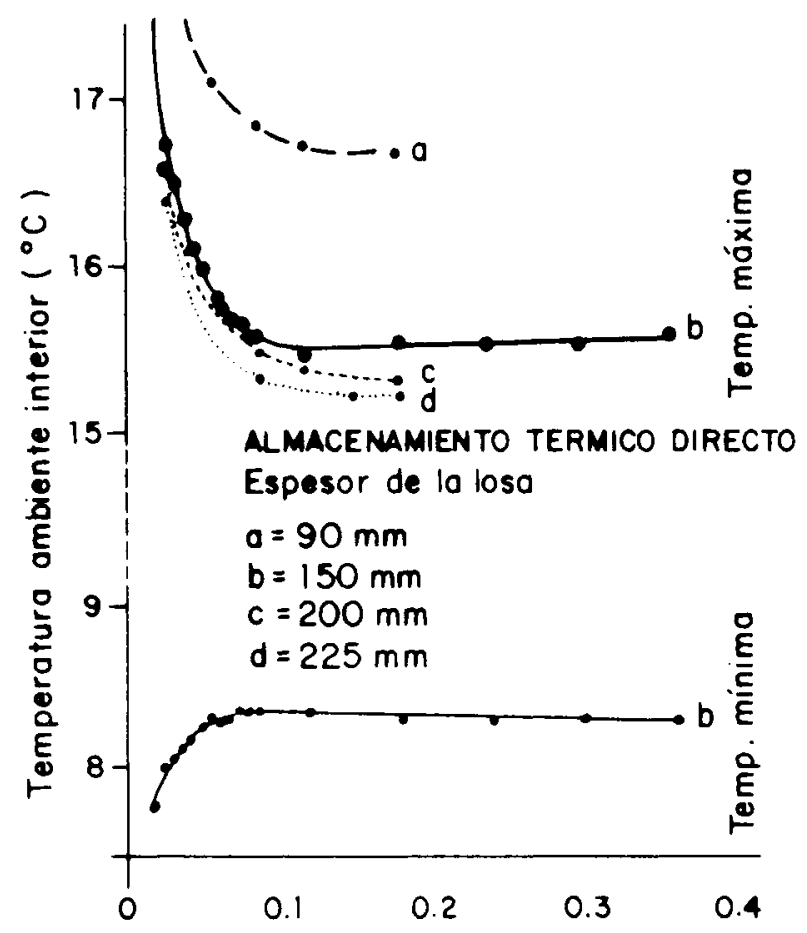

Fig. 3. Espesor del almacenamiento térmico indirecto $(m)$.

No sólo habrá que hablar de la masa térmica acumulada, sino también de su distribución, en la que entran a jugar un papel importante la ornamentación interior, mobiliario, etc. que conducen a una elevación del nivel de inercia térmica.

Sobre este punto en concreto, nos referiremos a los trabajos que llevamos a cabo en el Instituto dentro del equipo de investigación "Ahorro de Energía en la Edificación" hace unos años sobre tres módulos habita. cionales (18) que tenían como único elemento difen. ciador los muros perimetrales del cerramiento.

Los módulos estaban construidos con análoga cubierta y forjado, pero los cerramientos laterales eran de estructura ligera, media y pesada, a los que se les asignaron muros I, II y III respectivamente.

En el interior de cada módulo y durante el mismo período de tiempo se introdujo una masa acumuladora térmica constituida por $1 \mathrm{~m}^{3}$ de ladrillo cerámico perforado, con tres disposiciones diferentes a lo largo del proceso experimental, teniendo en cuenta que durante el mismo periodo de tiempo en tres módulos habia idéntica distribución de masa interna.

Las disposiciones eran las siguientes:

- Masa concentrada en el centro de la habitación.

- Masa distribuida sobre los cerramientos perimetrales opacos.

- Masa adosada al cerramiento orientado al Este.
TABLA IX

\begin{tabular}{|l|r|r|r|}
\hline \multirow{2}{*}{$\begin{array}{c}\text { Posición de la } \\
\text { masa acumuladora }\end{array}$} & \multicolumn{3}{|c|}{ MÓDULO } \\
& \multicolumn{1}{|c|}{ I } & \multicolumn{1}{c|}{ II } & III \\
\hline Concentrada & 70 & 90 & 131 \\
Distribuida & 80 & 122 & 149 \\
Adosada al Este & 104 & 146 & 173 \\
\hline
\end{tabular}

Los índices térmicos medios de cada módulo, de acuerdo con la disposición de la masa térmica, son los indicados en la tabla IX.

Con esta estructura se dispuso en cada módulo un termoconvector con control ambiental termostático para mantener la temperatura interior a $20 \pm 2^{\circ} \mathrm{C}$, y se sometió a cada módulo a un régimen intermitente de calefacción durante 18, 16 y 12 horas diarias, con el fin de poder apreciar la influencia de la inercia térmica en la oscilación de la temperatura interior.

Los resultados que se obtuvieron pueden observarse en la figura 4, donde se aprecian las relaciones existentes entre las amplitudes de las temperaturas del ambiente interior de los módulos y la temperatura media diaria exterior, respecto de la inercia térmica de cada módulo y el tiempo de calefacción.

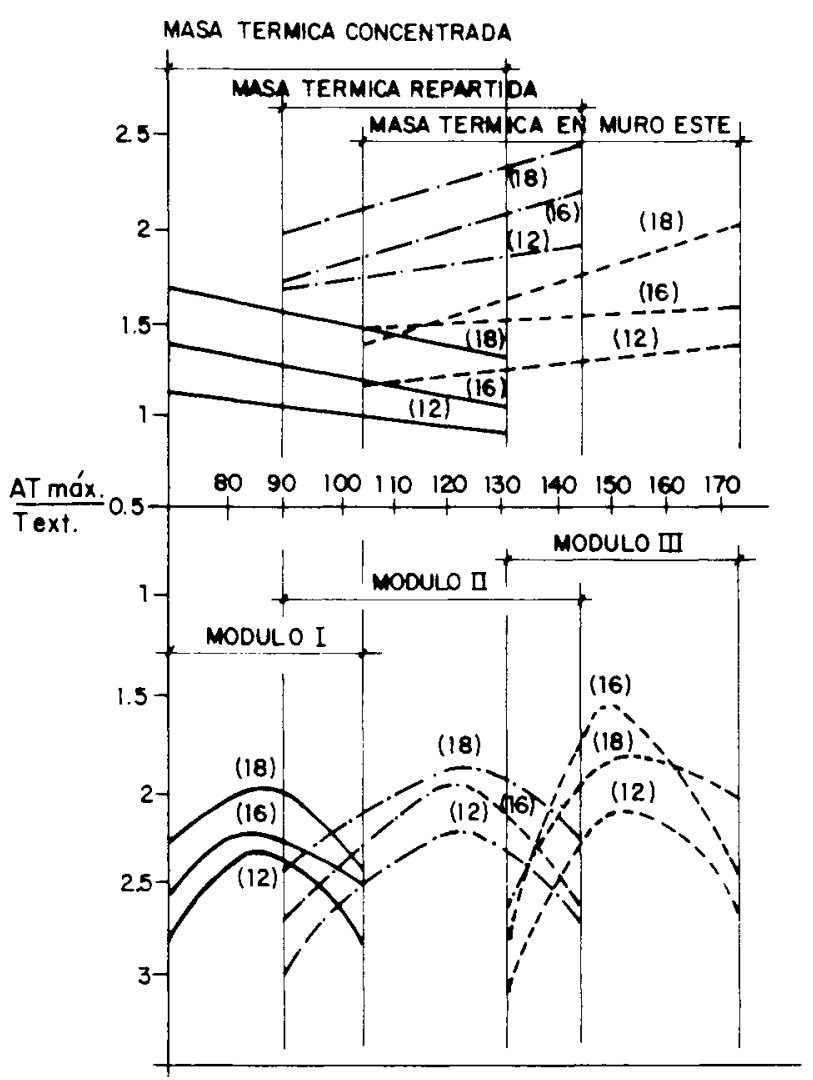

Nota.-Los números entre paréntesis indican el tiempo de intermitencia de la calefacción.

Fig. 4. Variación de la temperatura interior. 
Informes de la Construcción, Vol. 43 n. ${ }^{\circ}$ 416, noviembre/diciembre, 1991

Al observar la figura 4 se puede deducir que cuando la masa acumuladora se concentra en el centro de los módulos, o sobre una de las caras, la caida de la temperatura del aire interior (mínimos) es menor que cuando esa masa térmica se distribuye lo más posible sobre los muros perimetrales. En todos los casos, excepto en el módulo III, el tiempo de intermitencia del sistema de calefacción afecta a la variación de la amplitud de la temperatura del aire interior de una forma regular y no muy significativa.

\section{ACUMULACIÓN CON CANTOS RODADOS}

Centrándonos en el sistema de acumulación mediante cantos rodados, en el Instituto se ha desarrollado un trabajo sobre la base de un estudio comparativo entre dos casetas con disposiciones constructivas análogas, en los que se tomaba como elemento captador de energia solar un invernadero adosado a la fachada Sur, y la única diferencia estribaba en que una de las casetas disponia de un sistema acumulador a base de cantos rodados que estaba adosado al cerramiento Este de la caseta.

El estudio fue realizado en las instalaciones del Instituto (Madrid) en la época invernal, y tiene como principal objetivo analizar el ahorro energético que se origina con la utilización del sistema acumulador, cuando se utilizan períodos de calefacción continuada durante las 24 horas o bien intermitentes con períodos de utilización de 18, 12 y 10 horas de funcionamiento. La calefacción en cada caseta era proporcionada mediante un sistema de convector eléctrico de $1.000 \mathrm{~W}$ de potencia con regulación termostático ambiental, manteniendo la temperatura ambiente a $20 \pm 2^{\circ} \mathrm{C}$.

\subsection{Características constructivas de las casetas}

Las dos casetas (fotos 4 y 5), estaban situadas dentro del área del Instituto de forma que no recibiesen sombra arrojadas durante el período de experimentación.



Foto 4.-Vista de la caseta con invernadero sin acumulación térmica.

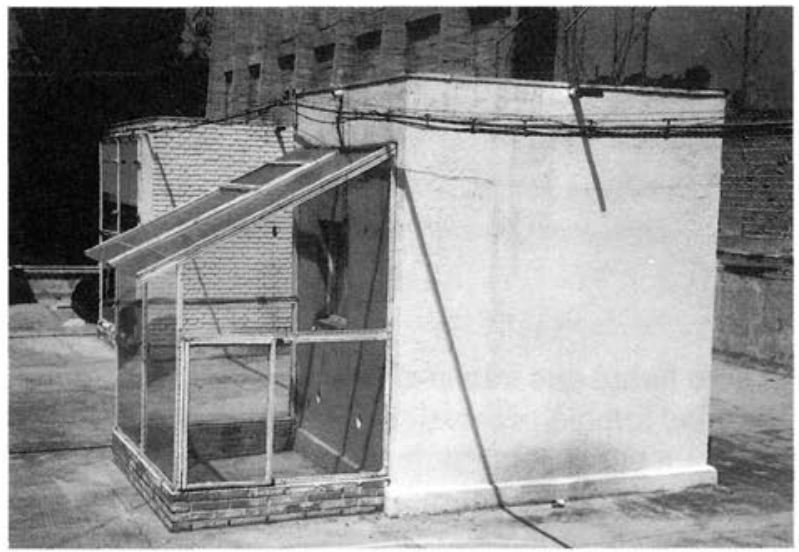

Foto 5.-Caseta con acumulación térmica adosada a la fachada Este.

La superficie interior era de $9 \mathrm{~m}^{2}$ con una altura media de 2,62 m, disponiendo de un forjado solado a base de terrazo y una cubierta plana con protección pesada.

Las características generales, tanto técnicas como de composición de los cerramientos de las casetas, fueron las siguientes:

\section{CERRAMIENTO}

\begin{tabular}{|c|l|c|c|c|}
\hline $\begin{array}{c}\text { ESPESOR } \\
(\mathbf{m})\end{array}$ & \multicolumn{1}{|c|}{ MATERIAL } & $\begin{array}{c}\mathrm{s} \\
\left(\mathbf{k g} / \mathbf{m}^{3}\right)\end{array}$ & $\begin{array}{c}\lambda \\
(\mathbf{W} / \mathbf{m K})\end{array}$ & $\begin{array}{c}\mathbf{C p} \\
(\mathbf{J} / \mathbf{k g K})\end{array}$ \\
\hline 0,013 & Placa yeso - cartón & 800 & 0,18 & 920 \\
0,03 & Aislamiento de poliestireno expandido & 25 & 0,033 & 1.590 \\
0,03 & Cámara de aire & 1,29 & - & 1.000 \\
0,12 & Ladrillo macizo & 1.800 & 0,87 & 1.380 \\
\hline
\end{tabular}

Coeficiente de transmisión de calor $\mathrm{K}=0,68 \mathrm{~W} / \mathrm{m}^{2} . \mathrm{K}$

Volumen del invernadero adosado a la fachada Sur $=6,6 \mathrm{~m}^{3}$.

Puerta de madera de acceso situada en la fachada Norte $=1,14 \mathrm{~m}^{2}$.

Ventana de carpinteria de madera en fachada Sur $=0,6 \mathrm{~m}^{2}$. 
TECHO

\begin{tabular}{|l|l|c|c|c|}
\hline $\begin{array}{c}\text { ESPESOR } \\
(\mathbf{m})\end{array}$ & \multicolumn{1}{|c|}{ MATERIAL } & $\begin{array}{c}s \\
\left(\mathbf{k g} / \mathbf{m}^{3}\right)\end{array}$ & $\begin{array}{c}\lambda \\
(\mathbf{W} / \mathbf{m K})\end{array}$ & $\begin{array}{c}\mathbf{C p} \\
(\mathrm{J} / \mathbf{k g K})\end{array}$ \\
\hline 0,013 & Placa yeso - cartón & 800 & 0,18 & 920 \\
0,03 & Poliestireno expandido & 25 & 0,033 & 1.530 \\
0,12 & Forjado cerámico & 1.250 & 0,4 & 880 \\
0,02 & Mortero de cemento & 2.000 & 1,4 & 1.050 \\
0,0015 & Impermeabilizante & 1.100 & 0,19 & 1.680 \\
0,05 & Gravilla & 1.700 & 1,21 & 920 \\
\hline
\end{tabular}

Coeficiente de transmisión de calor $\mathrm{K}=0,66 \mathrm{~W} / \mathrm{m}^{2} \mathrm{~K}$.

PISO

\begin{tabular}{|l|l|c|c|c|}
\hline $\begin{array}{c}\text { ESPESOR } \\
(\mathbf{m})\end{array}$ & \multicolumn{1}{|c|}{ MATERIAL } & $\begin{array}{c}\mathrm{s} \\
\left(\mathbf{k g} / \mathbf{m}^{3}\right)\end{array}$ & $\begin{array}{c}\lambda \\
(\mathbf{W} / \mathbf{m K})\end{array}$ & $\begin{array}{c}\mathbf{C p} \\
(\mathbf{J} / \mathbf{k g K})\end{array}$ \\
\hline 0,02 & Solado de terrazo & 2.000 & 1,2 & 1.000 \\
0,03 & Mortero de cemento & 2.000 & 1,40 & 1.050 \\
0,007 & Baldosin catalán & 2.000 & 1,05 & 840 \\
0,03 & Mortero de cemento & 2.000 & 1,40 & 1.050 \\
0,20 & Forjado cerámico & 1.250 & 0,4 & 880 \\
0,02 & Enlucido de yeso & 800 & 0,30 & 1.000 \\
\hline
\end{tabular}

Coeficiente de transmisión de calor $\mathrm{K}=1,17 \mathrm{~W} / \mathrm{m}^{2} \mathrm{~K}$. Coeficiente de transmisión térmica global de la caseta. $\mathrm{K}_{\mathrm{G}}=0,74 \mathrm{~W} / \mathrm{m}^{2} \mathrm{~K}$.

\subsection{Sistema de almacenamiento térmico}

El sistema de almacenamiento térmico, a base de cantos rodados, tenía un volumen total de $1,6 \mathrm{~m}^{3}$ y estaba adosado a la fachada Este hasta una altura media de $55 \mathrm{~cm}$. Se utilizaron cantos rodados de dimensiones comprendidas entre 7 y $15 \mathrm{~cm}$, que fueron seleccionados entre los que presentaban una superficie más redondeada, con el fin de disminuir los fenómenos de pérdida de carga en el interior del almacenamiento.

El tamaño de la piedra afecta de forma notable tanto al intercambio de calor, como a la pérdida de carga, de tal forma que con tamaños pequeños de piedras aumenta la superficie de intercambio calorífico y, como consecuencia, la transferencia térmica; pero por otra parte también aumenta la pérdida de carga.

Generalmente el volumen total ocupado por los cantos rodados, en relación al total del recinto almacena. dor, es del 40 al $60 \%$.

(c) Consejo Superior de Investigaciones Científicas Licencia Creative Commons 3.0 España (by-nc)
El primer estudio analítico térmico sobre este campo fue llevado por el Dr. Schumann (19) tomando como base las dos ecuaciones siguientes:

$$
\begin{aligned}
& (p . c p)_{f} \epsilon \frac{\partial T_{f}}{\partial L}=-\frac{(m C p)_{f}}{A} \frac{\partial T_{f}}{\partial x}+h_{v}\left(T_{c}-T_{f}\right) \\
& (p . c p)_{c}(1-\epsilon) \frac{\partial T_{c}}{\partial L_{l}}=h_{v}\left(T_{f}-T_{c}\right)
\end{aligned}
$$

donde:

$s=$ densidad

$\mathrm{Cp}=$ calor específico a presión constante,

$T=$ Temperatura,

$A=$ Superficie

$t \quad=$ Tiempo,

$\epsilon=$ Volumen de aire en el recinto almacenador,

$\mathrm{m}=$ masa

$h_{v}=$ Coeficiente de convección,

Subindices: $f=$ fluido y $c=$ cantos.

http://informesdelaconstruccion.revistas.csic.es 


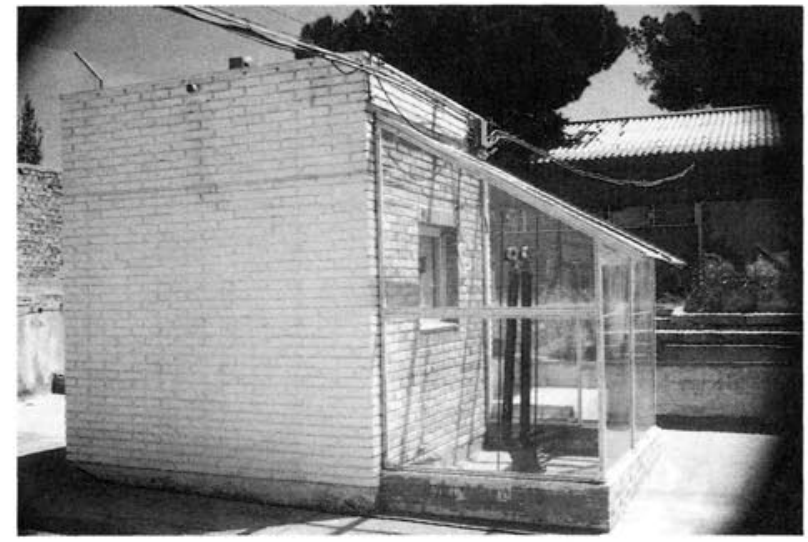

Foto 6.-Caseta con acumulación térmica, donde puede apreciarse el sistema del aire caliente al acumulador.

En dicho estudio se consideraban diversas simplificaciones como eran: en el carácter unidimensional de la transferencia térmica, propiedades constantes, no existía transferencia de masa, no se producian pérdidas térmicas con el exterior, asi como por estanquidad no existian gradiantes de temperaturas dentro del recinto acumulador, etc.

En el momento actual todavía no existe un procedimiento de cálculo aceptado, aunque se han efectuado varias modelaciones (8), (9). El procedimiento descrito en (17) sobre el diseño del almacenamiento, cálculo de la pérdida de carga y del equipo de ventilación, teniendo en cuenta el área del acristalamiento, del volumen habitable y el tamaño de los cantos rodados a utilizar, es el más sencillo y práctico de los distintos métodos de cálculo existentes.

En el caso que nos ocupa, el intercambio energético a los cantos rodados, es decir, la carga del acumulador se efectuaba mediante un dispositivo automático termostático, de tal forma que cuando la temperatura ambiente del recinto invernadero alcanzaba los $27^{\circ} \mathrm{C}$, se ponían en marcha dos ventiladores impulsores de $18 \mathrm{~m}^{3 / \mathrm{h}}$ cada uno, que enviaban por medio de un conducto de P.V.C. el aire caliente hacia el interior del sistema acumulador (foto 6 ).

El sistema acumulador estaba perfectamente aislado a base de planchas metálicas con espuma de poliuretano inyectado en su interior de $6 \mathrm{~cm}$ de espesor.

La entrada de aire caliente era por la zona inferior del recinto acumulador, y la comunicación hacia el local por la parte superior mediante dos orificios de 150 $\mathrm{cm}^{2}$ cada uno.

La descarga del acumulador se producía, por convección natural, cuando el nivel térmico de la caseta era inferior a la del recinto acumulador.

\subsection{Desarrollo de la experimentación}

En temporada de invierno, durante los meses de noviembre a febrero, y simultáneamente en ambas casetas, se fueron obteniendo datos higrotérmicos horarios mediante un sistema de adquisición de datos para los distintos períodos de calefacción establecidos, que tenían una duración entre 7 y 10 días, con un período de estabilización inicial en análogas condiciones de una semana.

También diariamente se tomaba lectura del consumo eléctrico realizado por el elemento calefactor, en los distintos períodos considerados.

Independientemente del ahorro energético que se experimente, hay otros factores importantes a valorar, como es el confort en el interior del local, ya que en estos sistemas sin actuación del usuario puede dar lugar a sobrecalentamientos internos, o bien a temperaturas inferiores a los del confort térmico.

En el aspecto de confort, únicamente se consideraron dos factores: temperatura y humedad relativa, de acuerdo con la escala de sensación higrotérmica que se tiene en un ambiente, que oscila entre un valor máximo $y=3$ (calor) a un valor mínimo $y=-3$ (frío). Referido a la ocupación de hombres y mujeres entre 1 a 3 horas en el local, dicha escala térmica tiene por expresión matemática la siguiente:

$$
y=0,25^{2} \cdot T_{s}+0,240 P_{v} \cdot 10^{-3}-6,859
$$

Simultáneamente a la toma de datos higrotérmicos, se obtenía el valor de sensación higrotérmica horaria que había en el ambiente en ese momento. Indudablemente, por todos es conocido que para mejor valorar el índice de confort térmico, habria también que considerar otros parámetros, como pueden ser: distribución de temperaturas en altura, temperatura radiante, velocidad del aire, etc.; para una primera consideración puede ser válida ya que, en condiciones normales, son los dos factores que tienen una mayor significación.

Con el fin de poder valorar conjuntamente estos dos aspectos de ahorro energético y confort térmico, de forma cuantitativa para establecer un estudio comparativo en este caso entre las dos casetas, se definió un indice conjunto lc definido en un período de $\mathrm{n}$ horas, por la expresión siguiente:

$$
I_{C}=C\left[\sum_{i=1}^{n}\left|Y_{i}\right|\right]
$$

donde:

$\mathrm{C}=$ Consumo eléctrico durante $\mathrm{n}$ horas,

$\mathrm{Y}=$ Escala de sensación higrotérmica. http://informesdelaconstruccion.revistas.csic.es 
TABLA X

\begin{tabular}{|c|c|c|}
\hline $\begin{array}{c}\text { RÉGIMEN DE CALEFACCIÓN } \\
\text { (HORAS) }\end{array}$ & $\begin{array}{c}\text { CASETA CON ACUMULADOR } \\
\mathbf{( k W} \mathbf{~ h )}\end{array}$ & $\begin{array}{c}\text { CASETA SIN ACUMULADOR } \\
\text { (kW h) }\end{array}$ \\
\hline 24 & 149,1 & 212,7 \\
18 & 109,5 & 132,4 \\
12 & 96,0 & 116,6 \\
10 & 84,7 & 90,8 \\
\hline
\end{tabular}

TABLA XI

\begin{tabular}{|c|c|c|}
\hline $\begin{array}{c}\text { RÉGIMEN DE CALEFACCIÓN } \\
\text { (HORAS) }\end{array}$ & CASETA CON ACUMULADOR & CASETA SIN ACUMULADOR \\
\hline 18 & 1 & 1,66 \\
12 & 1 & 1,27 \\
10 & 1 & 1,14 \\
\hline
\end{tabular}

Los valores de los consumos energéticos, durante el período de ensayo considerado, teniendo en cuenta el régimen de funcionamiento de calefacción de 24,18 , 12 y 10 horas, quedan reflejados en la tabla $X$.

Como puede observarse, el ahorro energético que se experimenta oscila entre un $42,1 \%$, en el caso de régimen continuo de calefacción, a un $7,2 \%$ en el caso de régimen intermitente de 10 horas de funcionamiento.

Si desarrollamos el indice conjunto definido anteriormente, y lo referimos al de la caseta con acumulador térmico que lo fijamos en la unidad, obtendremos para cada régimen de funcionamiento los índices conjuntos de la caseta sin acumulación térmica, según los datos que se indican en la tabla XI.

Del análisis global de las dos casetas consideradas, con la vista puesta en los datos obtenidos, puede deducirse lo siguiente:

- El ahorro energético considerable, que se experimenta con el sistema acumulador, podría ser más elevado si la extracción calorífica fuese controlada automáticamente en función de las necesidades del local y mediante sistemas de convección forzada, donde la descarga fuese más rápida.

- En la caseta sin acumulación se producen sobrecalentamientos, cosa que no ocurre en la caseta con acumulación, al ser almacenado el calor sobrante del invernadero y, de este modo, se evita la transmisión térmica hacia el interior del local.

\section{BIBLIOGRAFÍA}

(1) Esteban Sáiz, J.L. "La arquitectura popular como base de una arquitectura bioclimática. Aplicación al enfriamiento pasivo". Informes de la Construcción, Vol. 39 n. 385 Nov. 1986.

(2) ATECYR "Condiciones de diseño. Datos climáticos de Burgos". 1980.

(3) ATECYR "Condiciones de diseño. Datos climáticos de Córdoba". 1980.

(4) Comission of the european communities "Development and optimazation of Trobe's solar wall". EUR $6801 \cdot 1980$.

(5) Sander, D.M y Barakat, S.A. "Mass and Glass How much? How little?. ASHRDE JOURNAL. Nov. 1984.

(6) Sodha, M.S, Sawhney, R.L., Verma, R., Bonsal N.K. "Effect of limite thermal conductivity on the thermal performance of storage nedium. Bulding and Enviroment. Vol. 21 - 1986.

(7) Hoffman, M.E, Feldman, M. "Calculation of the thermal Response of building by the total thermal tine. Constant method. Building and Enviroment. Vol. 16 - 1981.

(8) Abhat, A. "Short term thermal energy storage" Energy and Building 3 - 1981. 
(9) Hariri, A.S., Ward I.C. "A review of Hernal storage systems ured in building applications" Building am Enviroment Vol. 23 - 1988.

(10) Bahadori, M.M. Haghighat F. "Thermal perfornance of adobe structures whit doned roofs and noist internid surfaces" Solar Energy Vol. 36-1986.

(11) Knowles, T.R. "Propostioning composites for efficient thermal storage wall" Solar Energy Vol. 31 - 1983.

(12) C.S.T.B. "Storage thermique par changement de phase aux temperatures de confort" n: 229. Cahier 1771 - 1982.

(13) Arkabi, H. y otros. "The effect of variations inconvection coefficients on thermal energy storage in building - Part I - Interior partition walls - Energy and Building n. $9 \cdot 1986$.

(14) Arkabi, H. y otros. "The effect of variations in convection coefficients on thermal energy storage in building Part II. Exterior massive wall and simulations. Energy and Building n. 10 - 1987.

(15) Boudeau, L. y otros. "Storage thermique de longue dureé par lits de cailloux". Cahier $1856 \mathrm{del}$ C.S.T.B. n. $240-1983$.

(16) Steemers, Theo "Passive solar energy as a fuel". Publication n. EUR 13094 EEC. Bruselas - 1990.

(17) European Passive Solar Handbook. Publication n? EUR 10683 EEC. Bruselas - 1988.

(18) Equipo de investigación "Ahorro de Energía en la Edificación". "Bases para el Diseño Solar Pasivo". Madrid - 1983.

(19) T.E.W. Shumann, Heat tranfer: A liquid flawing thorough a porons medio. J. Franklin Inst. 208 . 405 - 1929

(20) Steemers, Theo, C.E.C., DC XII, Passive Solar Energy as a Fuel. 1990 - 2010, Brussels - Luxemburg - 1990.

\title{
monografía del ICCET/CSIC ( . $\left.^{\circ} 405\right)$
}

\section{RECOMENDACIONES PARA LA FABRICACIÓN, PUESTA EN OBRA Y CONSERVACIÓN DE BLOQUES PREFABRICADOS DE HORMIGÓN}

\author{
MARINA A. ALVAREZ ALONSO \\ Dra. Arquitecta \\ ICCET/CSIC/ESPANNA
}

Madrid, marzo 1991

Esta monografía aborda diversos aspectos relativos a la fabricación de bloques y ejecución de albañilerías a base de bloques de hormigón. Tales aspectos indican diversos análisis, desde un estudio de la Normativa hasta el estudio del proyecto y ejecución de las fábricas, pasando por el análisis en términos de unidad de albañilería (bloque).

Las principales cuestiones estudiadas son las siguientes:

- Análisis de la Normativa ISO, EN, UNE; así como diversas Normas internacionales.

- Estudio de los materiales constitutivos, tratamientos, características y clasificación de los bloques de hormigón.

- Estudio de morteros de unión correspondientes a configuraciones usuales de la albañilería de bloques de hormigón.

- Análisis del proyecto y ejecución de albañilerías a base de bloques de hormigón.

Como síntesis se recogen conclusiones de los aspectos analizados y, en base a ellos, se han establecido criterios sobre las posibilidades de aplicación del sistema considerado. 